\title{
Individual canine retraction: RCT comparing Mulligan bypasses arch and Active laceback ligatures
}

\author{
Dr. Chetan. $S^{1}$, Dr. Gopla Krishna B.R ${ }^{2}$ Dr.Naveen Shamnur ${ }^{3}$ Dr. Anup Singhvi ${ }^{4}$ \\ ${ }^{1,2}$ (Assistant Professor,Department of Orthodontics, College of Dental Sciences,Davangere,India) \\ ${ }^{3}$ (Professor,Department of Orthodontics, College of Dental Sciences,Davangere,India) \\ ${ }^{4}$ (Post Graduate Student,Department of Orthodontics, College of Dental Sciences,Davangere,India)
}

\begin{abstract}
:
Objective: To compare the efficiency and effectiveness of Active laceback ligatures with that of Mulligan bypass arch for the amount of retraction, tipping and rotation. Materials and Methods: 20 patients were selected for the study who required upper $1^{\text {st }}$ premolar extraction for decrowding. All patients were treated with $3 M$ Gemini - MBT 0.022" metal brackets. Patients were divided into 2 groups of 10 patientsin each group. Group 1 was treated with active laceback ligature and group 2 with Mulligan bypass arch. Changes were measured on the cast with a digital vernier caliper. Student 't'test was used to determine the mean differences between the two groups for the amount of retraction, tipping and rotation. Results: Significant distal movement of Canine occurred in both the groups. Movement of canine was more in group 2 but distal tipping of canine and distopalatal rotation of the molar was more in group 1. These differences were mainly attributed to the arch wire material and type of force. Conclusion: Mulligan bypass arch group provided a more controlled and faster tooth movement when compared to active laceback ligature.
\end{abstract}

Keywords: Active Laceback ligature, Individual Canine retraction.,Mulligan bypass arch.

\section{INTRODUCTION}

Cases where incisors are crowded, decrowding are usually done by $1^{\text {st }}$ premolar extraction and distalization of canines. Distalization of canine can be done by various methods and with the help of various materials like: active tie backs, niti coil springs, active lacebacks ${ }^{1}$, bypass arches, loop mechanicss, mini implants, rare earth magnets, lasers, periodontal alveolar distraction.

Laceback ligatures are usually .009 " or .010 " stainless steel material which are tied in figure of 8 pattern running from molar, throught premolar into canine. ${ }^{2}$ When these ligatures active causes retaction. ${ }^{3}$ Mulligan bypass arch are usually made with .018" round stainless steel archwire. Here incisors are bypassed and anchor bend is given anterior to molar. ${ }^{4}$

The aims of this study were to investigate the amount of retraction, tipping and rotation of canine during its retraction by active laceback ligature and bypass arch.

\section{Materials and Methods}

20 patients were selected for the study, all the patients had anterior crowding and orthodontic treatment was planned with extraction on $1^{\text {st }}$ premolars, individually retract the canine and align the anteriors.

The patients were divided into 2 groups: group 1 with 10 patients treated with active laceback and group 2 with 10 patients treated with bypass arch. All the patients were treated with MBT 0.022" slot 3M Unitek Gemini metal brackets. TPA was given in all patients.

Active lacebacks were made of 0.009-inch ligature wire (3M Unitek, Monrovia, CA).Canines were retracted using active lacebacks which were reactivated once in 4 weeks until canine was retracted allowing incisor alignment. Fig 1

Mulligan bypass arch was made using 0.018 " SS wire. Canines were retracted with the help of e chain, which were changed once in 4 weeks until canine was retracted allowing incisor alignment. Fig 2

Patients were evaluated and readings were taken on day 1 before retraction was started (T0) and 12 weeks later (T1). At each appointment, impressions were made to obtain dental casts. All the measurements were taken on the caste. ${ }^{5,6}$

Measurements were taken on both right and left side and each measurement was taken twice and mean of two were recorded. All measurements were done by a single investigator.

The amount of tooth movement was measured on the caste from the tip of canine cusp to buccal groove of $1^{\text {st }}$ molar with a digital vernier caliper. ${ }^{6}$ Amount of tooth movement was calculated by difference in T0 and T1 and mean values were calculated. Fig 3

Degree of canine tipping was measured by the angle formed between occlusal plane and long axis of canine. Change in the tip was calculated by subtracting T1 from T0 and mean values were calculated. Fig 4 
Degree of canine rotation was measured by the angle formed between mid palatine suture and the line passing through distal and mesial contact points of the canine. ${ }^{7}$ Change in rotation was calculated by difference between $\mathrm{T} 0$ and $\mathrm{T} 1$ and mean values were calculated. Fig 5

All measurements were tabulated and statistically analyzed for both types of retraction.

Mean and SD was calculated for group 1 and group 2, for amount of space closure, tipping and rotation at T0 and T1. Differences betwees means of T0 and T1 was then calculated. Results are shown in Table 1.

Student ' $t$ 'test was used to compare differences between the two groups for the amount of retraction, tipping and rotation, then the p value was calculated. Results are shown in Table 2.

\section{Results}

Mean and SD for both groups and all three variables were calculated separately. Differences in the mean between $\mathrm{T} 0$ and $\mathrm{T} 1$ were calculated, values obtained are mentioned in Table 1. Comparison of the amount of space closure, tipping and rotation between two groups were calculated using student ' $t$ ' test, then the $p$ value was calculated to find out the significance, values are mentioned in Table 2.

Amount of space closure was measured in millimetres. Tipping and rotation was measured in degrees. Mean values between the groups were compared using student ' $t$ ' test. A ' $p$ ' value of less than 0.05 was considered statistically significant.

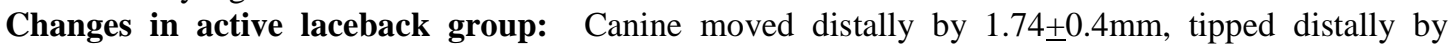
$5.9 \pm 2.07^{\circ}$ and rotated mesiobucally by $5 \pm 1.62^{\circ}$.

Changes in bypass arch group: Canine moved distally by $2.475 \pm 0.34 \mathrm{~mm}$, tipped distally by $2.95 \pm 1.27^{\circ}$ and rotated mesiobucally by $2.05 \pm 1.87^{\circ}$.

Comparison between groups: Statistically significant difference was seen in amount of retraction, tipping and rotation between both the groups. Amount of space closure was more in group 2, where as tipping and rotation was more in group1.

IV. FIGURES AND TABLES

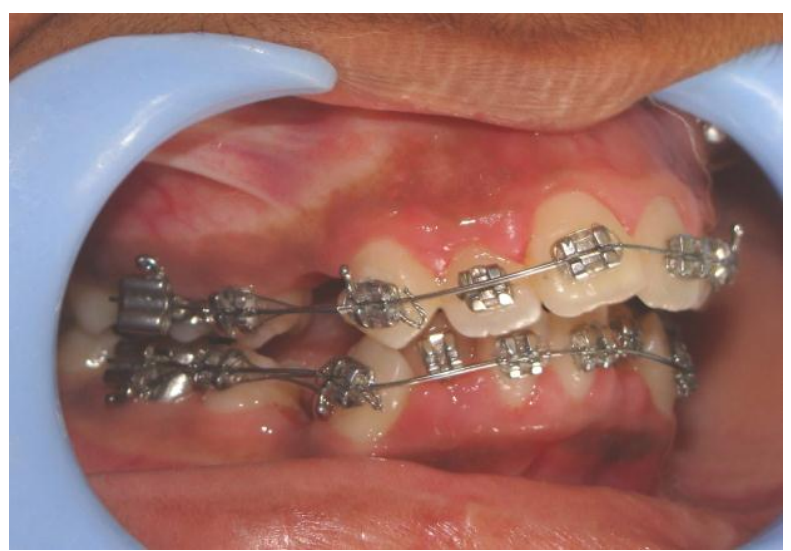

Fig 1: Canine retraction with Active laceback ligature

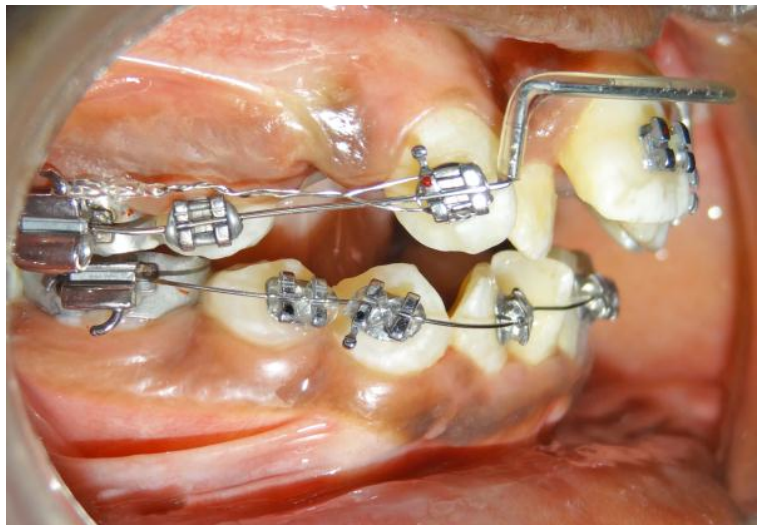

Fig 2: Canine retraction with Mullian bypass arch 


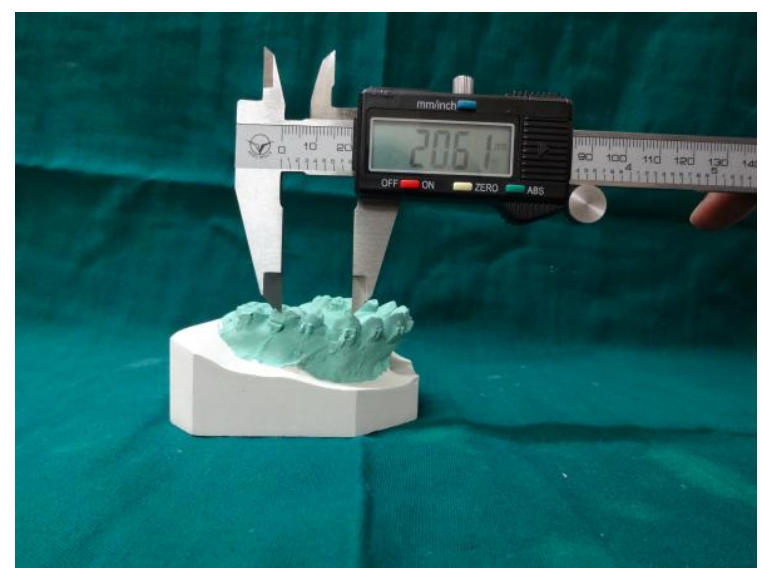

Fig 3: Measurement of amount of canine retraction using digital vernier caliper

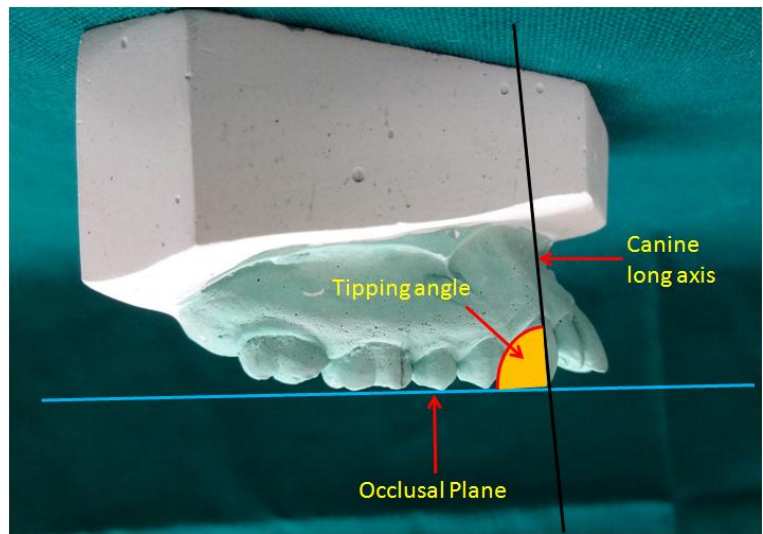

Fig 4: measurement of canine tip on the cast by angle fromed between occlusal plane and long axis of canine

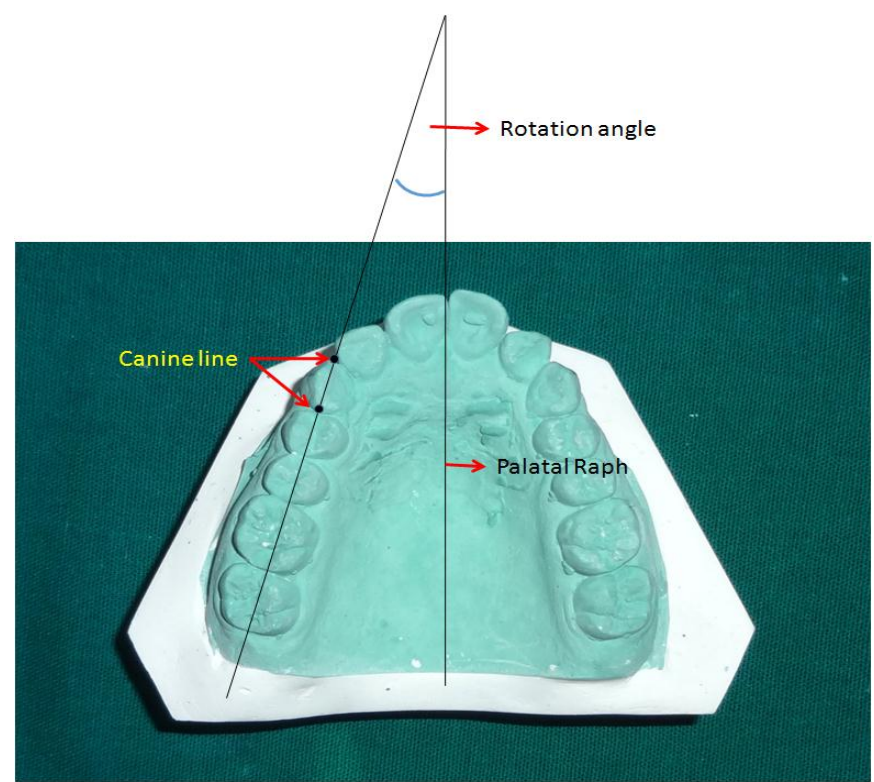

Fig 5: Measurement of canine rotation by the angle formed between midpalatal raphe and mesial and distal contacts of canine 
Table 1: Differences in the mean between T0 and T1 for the amount of space closure, tipping and rotation for both groups.

\begin{tabular}{|c|c|c|c|c|c|c|c|}
\hline & & Pre retraction $-\mathrm{T} 0$ & \multicolumn{2}{|c|}{ Post retraction $-\mathrm{T} 1$} & \multicolumn{2}{c|}{ Change } \\
\cline { 2 - 7 } & & Mean & SD & Mean & SD & D & SD \\
\hline \multirow{2}{*}{$\begin{array}{c}\text { Group 1 } \\
\text { Active laceback }\end{array}$} & Amount of Space closure & $22.5 \mathrm{~mm}$ & 1.63 & $20.76 \mathrm{~mm}$ & 1.54 & $1.74 \mathrm{~mm}$ & 0.433 \\
\cline { 2 - 7 } & Tipping & $92.2^{\circ}$ & 3.54 & $86.3^{\circ}$ & 4.31 & $5.9^{\circ}$ & 2.07 \\
\cline { 2 - 7 } & Rotation & $44.9^{\circ}$ & 3.32 & $39.9^{\circ}$ & 4.12 & $5^{\circ}$ & 1.62 \\
\hline \multirow{2}{*}{$\begin{array}{c}\text { Group 2 } \\
\text { Bypass arch }\end{array}$} & Amount of Space closure & $22.1 \mathrm{~mm}$ & 1.46 & $19.625 \mathrm{~mm}$ & 1.42 & $2.475 \mathrm{~mm}$ & 0.34 \\
\cline { 2 - 7 } & Tipping & $93.5^{\circ}$ & 3.88 & $90.55^{\circ}$ & 4.38 & $2.95^{\circ}$ & 1.27 \\
\cline { 2 - 7 } & Rotation & $44.4^{\circ}$ & 3.93 & $42.35^{\circ}$ & 4.17 & $2.05^{\circ}$ & 1.87 \\
\hline
\end{tabular}

Table 2: Comparision of amount of space closure, tipping and rotation between two types of canine retraction.

\begin{tabular}{|c|c|c|c|c|}
\hline & Type of retraction & & T value & P value \\
\hline \multirow{2}{*}{$\begin{array}{c}\text { Amount of space } \\
\text { closure }\end{array}$} & Active laceback & $1.74 \mathrm{~mm}$ & \multirow{2}{*}{.5 .916} & \multirow{2}{*}{.000} \\
\cline { 2 - 3 } Tipping & Bypass arch & $2.475 \mathrm{~mm}$ & 5.416 & \multirow{2}{*}{.000} \\
\cline { 2 - 3 } & Active laceback & $5.9^{\circ}$ & $2.95^{\circ}$ & \multirow{2}{*}{5.318} \\
\hline \multirow{2}{*}{ Rotation } & Bypass arch & $5^{\circ}$ & $2.05^{\circ}$ & \\
\cline { 2 - 3 } & Bctive laceback & Bypass arch & &
\end{tabular}

\section{Discussion}

In group 1 canine moved distally by $1.74 \mathrm{~mm}$, whereas in group 2 it moved by $2.47 \mathrm{~mm}$ which is statistically significant. These results clearly demonstrate that faster movement and more displacement of the canine are achieved in group 2. The reason for this is mainly because of different type of forces, i.e. group 1 had interrupted force and group 2 had continuous force. Studies have shown that tooth moves at a rate almost twice in continuous force than the interrupted force in duration of 3 months. ${ }^{8}$

In group 1 canine tipped by $5.9^{\circ}$, whereas in group 2 it tipped by $2.95^{\circ}$ which is statistically significant. Tipping was seen in both the groups because the line of action of force is passed occlusal to the center of resistance of the canine, causing distal tipping. The results indicate that canine tipping was less in group 2, which is due to 0.018 "SS wire used for retraction, whereas in group 1: 0.014"niti was used, which is flexible so allowed more tipping.

In group 1 canine rotated distopalatally by $5^{\circ}$, whereas in group 2 it rotated distopalatally by $2.05^{\circ}$ which is statistically significant. Rotation is seen in both the groups because the line of action of the force is passed buccal to the centre of resistance causing distopalatal rotation. The results indicate that canine rotation was less in group 2, which is due to 0.018 "SS wire used for retraction, whereas in group 1: 0.014"niti was used, which is flexible so allowed rotation. Ziegler and Ingervall in their study also observed distopalatal rotation of the canine during retraction. ${ }^{9}$

\section{Conclusion}

Active laceback ligature and Mulligan bypass arch both provide enough amount of canine retraction. When compared to the active laceback group, tooth movement in a given period of time was greater with Mulligan bypass arch, i.e. rate of tooth movement was faste and amount of distal tipping and distopalatal rotation was significantly less. Mulligan bypass arch group provided a more controlled and faster tooth movement when compared to active laceback ligature. Active laceback ligature is advantageous only when canine is mesially tipped and space required is $2-3 \mathrm{~mm}$ only.

\section{References}

[1]. Sureri MY, Turk T. Effectiveness of laceback ligatures on maxillary canine retraction. Angle Orthod. 2006; 76(6): 1010-1014.

[2]. Awni KM. Comparison Between Laceback and Tieback in Sliding Mechanics (an in vitro study). Al-Rafidain Dent J. 2012; 12(1): $148-152$.

[3]. Moresca RC,Vigorito JW, Dominguez GC, Tortamano A,Moraes DR, Moro A, Correr GM. Effects of Active and Passive Lacebacks on Antero-Posterior Position of Maxillary First Molars and Central Incisors. Braz Dent J. 2012; $23(4)$ : $433-437$.

[4]. Mulligan TS, Common Sense Mechanics, J clinical ortho,1980;14(12):855-86.

[5]. Irvine R, Power S, McDonald F. The effectiveness of laceback ligatures: a randomized controlled clinical trial. J Orthod. 2004 Dec;31(4):303-11.

[6]. Wahab RMA, Idris H, Yacob H and ARIffIn SHZ. Canine Retraction: A Randomised Clinical Trial Comparing Damon3 SelfLigating with Conventional Ligating Brackets. Sains Malaysiana. 2013 ; 42(2): 251-255.

[7]. Mezomoa MC, Limab ESD, Menezesb LMD, Weissheimerc A, Allgayerd S. Maxillary canine retraction with self-ligating and conventional brackets - A randomized clinical trial. Angle Orthod. 2011;81:292-297.

[8]. Daskalogiannakis J, McLachlan KR. Canine retraction with rare earth magnets: An investigation into the validity of the constant force hypothesis. Am J Orthod Dentofacial Orthop.1996;109:489-495.

[9]. Ziegler P, Ingervall B. A clinical study of maxillary canine retraction with are traction spring and with sliding mechanics. Am J Orthod Dentofacial Orthop. 1989;95(2):99-106. 